\title{
Mikhail Larionov: Rayonism and Radiant Matter
}

\author{
Ekaterina Bobrinskaya \\ Department of Fine Arts and Architecture \\ State Institute for Art Studies \\ Moscow, Russia \\ E-mail: ekaterina173@gmail.com
}

\begin{abstract}
The article focuses on several aspects of the theory and practice of rayonism in the work of Mikhail Larionov, which have to date remained at the periphery of art historians' interest. The bringing together of positivist science and occultism was one of the most paradoxical "avant-garde" features of fin-de-siècle culture. Like many European avantgarde artists, Larionov created the concept of rayonism based on the scientific and occult mythology of his time. The concept of painterly rayonism appeared in the context of research and practical experiments into the visualisation of invisible radiation.
\end{abstract}

Keywords-Mikhail Larionov; radiant matter; rayonism; russian avant-garde; abstract art; the intersection of scientific and occult ideas

\section{INTRODUCTION}

I will focus on several aspects of the theory and practice of rayonism in the work of Mikhail Larionov, which have to date remained at the periphery of art historians' interest. That notwithstanding, these "forgotten" sides of painterly rayonism cannot be considered of secondary importance. In my opinion, these elements of rayonism allow us to research many trends associated with the formation of modernist art, including: the emergence of new iconographical sources; the appearance of a new interpretation of the creative process and of the figure of the artist; and the creation of a new mechanism of myth-making based on contemporary technologies and scientific experiments. Mikhail Larionov's concept of rayonism is at the centre of all of these processes.

The bringing together of positivist science and occultism was one of the most paradoxical "avant-garde" features of fin-de-siècle culture. In his memoirs, Mikhail Matiushin noted: "The question of dimensions was important for everyone at the turn of the century, especially for artists. A huge amount was written about the fourth dimension. Everything new in art and science was considered to originate in the very depths of the fourth measure. There was a strong element of occultism in the mix" [1].This cultural atmosphere provided nourishment for numerous avant-garde experiments in art. Mikhail Larionov's rayonism was no exception. Like many European avant-garde artists, Larionov created the concept of rayonism based on the scientific and occult mythology of his time.

Today there are two main methods of describing and interpreting painterly rayonism. The first is formal. Here, a rayonist picture is a work of pure painterly matter. Larionov undoubtedly indicated the possibility of this approach. In the preface to the catalogue of the exhibition Target (1913) he wrote: "We have created our own style, rayonism, which involves spatial forms and making painting which is selfsufficient and lives by its own rules" [2].Nevertheless, on the periphery of such interpretations one often finds references to the "fourth dimension", a concept which was popular with members of the Russian avant-garde during the 1910s. [3].The second type of interpretation was proposed by Dmitri Sarabianov and taken up by other specialists (T. Levina, A. Inshakov). Sarabianov connected Larionov's rayonism to the tradition of Hesychasm and the particular concept of light on which it is based, i.e. to an archetypical or hidden, but very important, tradition in Russian and Orthodox culture which appears even in secular painting. In his article "Mikhail Larionov and the Makovets group", Sarabianov stressed the unconscious mechanism by which the layers of this archetypical tradition appear: "National mentalities form over centuries and make themselves known completely unexpectedly, most often independently of the position and desires of the subject of history" [4]. While refuting neither the formal approach nor Sarabianov's "Jungian" method, I would like to examine yet another context for rayonist painting.

\section{RADIANT MATTER}

In 1936, in a letter to Alfred Barr, director of the Museum of Modern Art in New York, Mikhail Larionov noted, not without disappointment: "Usually I am indifferent to what people think about various issues and about me personally. I am unconcerned about whether I first spoke of rayonism a long time ago or not. In any case, even today no one is talking about it, and if they are I think that you see that they do not mean rayonism. Abstract art is not rayonism. For that reason I am contacting you, as questions of the materialisation of spirit may be of interest"[5]. Larionov's phrase "materialisation of spirit" refers to a concrete and well-known term among spiritualists. Materialisation - and I emphasise here materialisation and not dematerialisation, which was of interest to Kandinsky - was, at the turn of the century, a central concern of various spiritualist practices and related scientific research. Spiritualism, which had formed within a particular subculture, with its own terminology, mythology and iconography, changed significantly at the beginning of the 20th century, having incorporated many 
methods and theories from positivist science. At that time, the combination of scientific knowledge and experimental methods with the mythologemes and fantasies of the occultists created a module for many cultural processes. It is important to note that the boundary between science and various forms of occult knowledge was significantly less strict and distinct than today. The appearance of the occult in the scientific sphere was not seen as the rational retreating before the irrational but as the final triumph of positivist science, which had at last acquired the possibility to study the most secret spheres of matter, thought and the human psyche. For their part, occultists and spiritualists attempted to use scientific discoveries to rationalise their explanations of secret phenomena. At the turn of the century, the interest in scientific, positivist methods of exploring the "materialisation of spirit" at spiritualist séances was very common. Many top scientists were involved, and the spaces where séances took place looked more like laboratories: they were full of equipment, including cameras to record the processes of radiation and materialisation.

In European culture, the turn of the century was marked by incredible discoveries which changed the accepted optical regimes and provided entry to the territory of the unseen. Xrays, the wireless telegraph, chronophotography and microphotography blurred the usual boundaries of the internal and external, the visible and the invisible, creating new models of communication. Towards the beginning of the 20th century a particular mythology, and even a particular culture, of radiation developed, based on experiences at spiritualist séances or in scientific laboratories. After late-19th-century discoveries such as X-rays, becquerels, and Marie and Pierre Curie's work on radium and polonium, many concepts appeared that were associated with radiation, the human body and various objects. Invisible radiant matter surrounded everything. The well-known sociologist Gustave Le Bon stated: "All bodies are a constant source of rays, visible and invisible, but always consisting of light"[6].Some of the popular theories of the time were no more than modern versions of Franz Mesmer's concept of universal fluid or Carl von Reichenbach's idea of odic light. However, there were also new versions, based on positivist scientific principles and new technologies: Prosper-Rene Blondlot's N-rays and Louis Darget's V-rays; Sergei Yurevich's Y-rays, radiated by the human organism; NaumKotik's "brain rays", which were connected to thought; Julian Ochorowicz's "hard rays", which he envisaged as a magnetic field radiated by living organisms; or St. Petersburg doctor Messira Pogorelsky's "physiological polar energy". These were just some of the hypotheses and mythologies connected with the phenomenon of radiation.

Radiant matter, invisible to the naked eye but detectable by equipment, surrounded all organisms and objects. Remaining invisible, it pointed to the existence of a particular dimension of reality. By the beginning of the 20th century, "radiant matter" and "radiant energy" would become popular means of interpreting a multitude of phenomena which had no rational explanation.1 I will give

At the beginning of the 20th century, all of the hypotheses and theories of radiation filtered quickly through academic publications to the just two examples. Cesare Lombroso connected the phenomenon of materialisation of spirit at spiritualist séances with a particular radiant state of matter, somewhat like radiation. He wrote of "radiant streams and shafts of light" which were detected during séances led by the famous medium Eusapia Palladino. The "spiritual organisms" which appeared during séances represented the fourth or radiant state of matter. According to Lombroso's hypothesis, during a séance the medium also gave off radiant matter. Its rays interacted with the radiant matter of the "spiritual organisms" or spirits and the combination of radiation gave birth to the phenomenon of materialisation, i.e. the appearance during séances of paradoxical organisms: "luminous clouds", body parts or whole figures. "Everything leads to the hypothesis that the spirit is made up of radiant matter", concludes Lombroso [7].Within the "biology of spirits" which the Italian researcher developed, he also underlined their radiant, illuminated nature.

There is another example. In 1907, the Russian researcher NaumKotik published a book of his experiments, in which he wrote about n-rays, "which appear in the subject's brain at the moment of thought and are then distributed in all directions"[8].According to his theory, "thought is accompanied by the discharge of radiant energy. This radiant energy has psychic and physical characteristics and should therefore be termed psychophysical energy" [9].Kotik believed that clairvoyance and telepathy were possible thanks to radiant energy, which was similar to radiation.

At the beginning of the 20th century, the world was full of life invisible to the eye: the movements or vibrations of radiant matter and the currents of radiant energy. As was written at the time: "Everything living, everything real is immersed in an ocean of radiant energy" [10]; "All bodies give off rays and as such the entire universe is criss-crossed by waves of rays"[11].The idea of the surrounding space being filled with numerous intersecting rays, which create new radiant forms, is one of the main points in the concept of rayonism: "Bearing in mind not the objects themselves but the sum of the rays they emanate, we can create a picture in the following way: the sum of rays from object $A$ intersects with the sum of rays from object B and in the space in between a certain form appears, created by the will of the artist"[12].If in the 1870 s and 1880 s the possibility of seeing radiant matter was accessible only to particularly sensitive individuals during mediumistic trances or under hypnosis, at the beginning of the 20th century a new apparatus allowed everyone to enter the hidden world of radiation. X-ray machines became a popular attraction and earlier fantasies of irradiation became an everyday occurrence associated with the miracles of domestic comfort and modern medicine.

press, transforming into sensational and generally accessible knowledge of modern scientific discoveries. Such publications appeared regularly in the Russian press, for example "G-e N. Chelovekistochnik N-luchei", Peterburgskayagazeta, 27 December 1911, 3; "Nemo. Chelovekispuskarn N-luchei”, Raneeutro, 5 January 1912, 4. 


\section{RAYONISM AND THE ICONOGRAPHY OF RADIATION}

The concept of painterly rayonism appeared in the context of research and practical experiments into the visualisation of invisible radiation. In the above-mentioned letter to Alfred Barr, Larionov insistently stressed the link between rayonism and various types of radiation: "Rayonism does not investigate questions of space and movement. It means Light as the origin of the material and of various types of radiation: radio, infra-red, ultraviolet, etc." Several lines later, he writes: "[...] rayonism means radiation of all types: radioactivity, the radiation of human thought. Because the expenditure of our brain, its decay (decomposition) is its giving off rays, its radioactivity" [13].

I note that Larionov's last statement coincides almost word-for-word with Kotik's theories and with the views which were actively repeated in the literature of the turn of the century. What follows is a typical statement from a popular book of the time: "The work of the higher nerve centres, intellectual work, involves n-rays"[14].

By the beginning of the 20th century a particular iconography of the light radiation of people and various bodies was formed. Its sources were varied: mass occult journals, illustrations in scientific literature, a vast photographic archive made during spiritualist séances, photographs of irradiated people made by Hippolyte Baraduc and Louis Darget and others. This set of images had an important quality. It was positivist, documentary evidence of the invisible. Photography played a particular role in this iconography. Like a medium in a trance, photographic plates can capture and make visible the invisible. This magical quality of photography, and not simply its documentary nature, played an important role in fin-de siècle culture [15]. It enabled the opening up to the eye of the visible for contemplation and, in addition, created new vectors for painting.

The early stage of rayonism in Larionov's work often follows the widespread iconography of radiation. I will not only some of the main motifs. Bunches of rays emerging from the eyes, nose, ears and mouth of a person is one of the most common motifs in illustrations of research of a scientific-occult nature. In "realistic rayonism", as Larionov called it, such motifs can be found repeatedly (Bull's Head, 1912, State Tretyakov Gallery; Male Portrait (Rayonist Construction) in the book Pomade, 1913; Rayonist Portrait in the book Half-Dead, 1913). Moreover, Larionov's rayonist portraits create a particular conception of an open, permeable human body (Portrait of Natalia Goncharova, 1912; Woman in a Hat in the book Pomade, 1913; Person, 1910s, State Literary Museum, Moscow). This new anthropology in Larionov's works is born from the intersection of scientific and occult ideas of humankind, on the territory where the impermeable borders of the material world disappear and radiant matter and energy appear. William Crooks wrote about the new form of measuring reality opened up by "radiant matter": "We have touched the borders where matter and power seem to blend, the shadows between the known and the unknown" [16].
There is another motif of Larionov's rayonism which refers to the iconography of radiation. In his book L'Exteriorisation de la sensibilité, Albert de Rochas stated, based on experiments by various researchers: "Different parts of the body have different colours... right hands glow with a blueish light, left hands are dark red"; "the right side of the human body has an overall blue tone. The eyes, ears, nostrils and lips give off the same colour when irradiated...The left side of the body gives off a red radiation through the sense organs" [17]. Similar polar red and blue divisions of space can be seen in a number of Larionov'srayonist works and they follow the aforementioned rule of blue being mainly on the right of the picture and red on the left (Rayonist Lines, 1912, Nesterov Bashkir State Art Museum, Ufa).

And finally, one more aspect of the iconography of radiation. At the turn of the century, electricity and radiant matter or radiant energy were often directly connected. In Russia, the most famous researcher in this field was Yakov Nardkevich-Iodko, who devised his own "method of registering the energy given off by a living organism under the influence of an electric field". He called this method electrography. Nardkevich-Iodko's photographs were wellknown in Russia and Europe at the time. They were often shown at photographic exhibitions and during his public lectures, and were published in both specialist journals and popular magazines such as Niva. Nardkevich-Iodko considered his images of electrical discharges, made without using a camera, to be "micrographic traces of electrical currents" issuing from the human body. He wrote: "Here electricity itself plays the role of illustrator, forcing the particles (or tiny atoms of matter) to be distributed in a certain order". [18] In 1899, Messira Pogorelsky, in his essay "Electrophotosphens and energography", [19] devised his own system of recording electrical radiation of the human body: the energogram. His alphabet of energography was based both on his own images and on those of NardkevichIodko. The tree-like forms, "light clusters", and straight or zigzag rays on many energograms create fantastic abstractions or unusual landscapes of the invisible. Certain motifs and compositional principles of these images are comparable to a number of Larionov and Goncharova'srayonist landscapes, in which bunches of rays or "light clusters" and branched, tree-like forms reference the iconography of electrical currents (Natalia Goncharova, Electrical Chandelier, 1913, State Tretyakov Gallery, Moscow; Sea. Rayonist Composition, 1912-1913, Stedelijk Museum, Amsterdam; Mikhail Larionov, Rayonist Landscape, 1912-1913, State Russian Museum, St. Petersburg; Rayonist Composition, 1912-1913, private collection, Milan). Like energograms, rayonist images capture the energetic contour of the world, which the eye cannot see.

Larioniov's rayonism does not just repeat various iconographic sources but synthesises them into a particular artistic structure where the mythology of radiation and scientific and occult research is simply a starting point. Nevertheless, these traces enable us to establish the context in which Larionov's painterly concept was formed. 


\section{The Creative Process AND the Figure of the} ARTIST

Another important aspect of rayonism is connected with a new interpretation of both the creative process and the figure of the artist. The space around us is filled with invisible forms, emanations. Using will and imagination, the artist can "see" them and transfer them to the canvas. As Larionov wrote in one of his late texts:

There are infinite quantities of such forms ... Let us say that between a house, a wall and a garden there is an empty piece of air called sky. With no clouds, nothing. The artist imagines within that space a certain form and depicts it on paper or canvas, a form which has nothing in common with the garden, house or wall. The artist surmises that within this space there is an infinite quantity of rays of various objects, known and unknown to him, that come from ... the cosmic space. He surmises that the whole so-called space is filled with forms unknown to us ... The artist only needs to wish to do so and he can coax (the form) from the infinite space. These forms are rayonist [20].

In this interpretation, the artist is a type of medium, with whose help the "materialisation of the soul" takes place. Like a medium, the artist makes contact with the invisible, seeing forms which are hidden from the eye and giving them a material existence in the picture. A rayonist picture can be compared to a light-sensitive plate which allows us to capture prints of the invisible.

Larionov's description of the existence within the surrounding space of invisible forms refers to a popular finde-siècle concept. Ether was considered to be a light-bearing, universal milieu through which radiant matter and radiant energy moved. The material world was thought to be made up of various thicknesses of ether. I stress that the concept of ether was accepted within the scientific world at the time and was included in physics textbooks as a valid scientific theory. In 1875, in the book The Unseen Universe, the physicists Stewart Balfour and Peter Tait proposed interpreting ether as a depository for various images, sensations, forms and feelings (they described ether as "a way in which the universe conserves a memory of the last")[21].They saw ether as a space of memory, the light waves of which were imprinted with events, feelings, thoughts and images. Ether was an environment which could host invisible radiant forms. Charles Hinton, whose work was familiar to Russian artists through the publications of Peter Ouspensky, also described ether as a type of phonograph or a cosmic depository for all kinds of images. 2 In passing I note that Hinton's theories focused on the practice of visualisation, working with the imagination to penetrate the invisible fourth dimension. For Larionov, working with the imagination — the resolute effort of the artist which opens up access to invisible forms - also played an important role. He stressed that rayonism meant "not objects reflected (as in a mirror), but imagined,

Charles Hinton. The Fourth Dimension (London: Swan Sonnenschein\& Co., 1906). Published in Russian as Chetvertoeizmerenie i era novoimysli (Petrograd: Knigoizdatel'stvoNovyichelovek, 1915). Hinton's ideas were examined in detail in Ouspensky's book TertiumOrganum. Klyuch k zagadkammira (St. Petersburg, 1911). non-existent forms which could be created by the will of the artist from the intersection of an infinite number of rays from various objects, which are dissimilar to each of these objects"'[22].

Finally, another important aspect of the theory of rayonism is connected with the new interpretation of the figure of the artist. The rayonist picture does not simply derive images from the invisible ephemeral archives of form. It appears as a result of the interplay of external rays and the radiating thoughts of the artist. Rayonist pictures are born from the intersection of radiant thoughts and the ether's invisible radiant forms. As Larionov wrote: "If light, radio and other rays are material and if our thoughts are also a form of radiation, then all that is needed is the interaction of both types of rays and that of which I speak will come to pass" $[5$, p. 98].It is this aspect of rayonism, which turns the artist into a paradoxical apparatus that connects the invisible and visible world, thought and matter, which Larionov had in mind when he wrote of the presence of rayonism over and above ordinary abstract painting. According to him, rayonism speaks of "the transfer of the purely philosophical field to the purely physical"[23].Ilia Zdanevich noted this side of rayonism in his book about Larionov and Goncharova: "rayonism is also enriched by the fact that it takes into account not only that which is externally radiated but also the internal spiritual"'[24].

Radiant matter radiates during the process of thought and physical activity.3 And in the same way that other forms of radiation can be recorded on photographic plates, thoughts can leave their traces on light-sensitive surfaces. At the turn of the century, a wide range of researchers conducted scientific experiments aiming to record thoughts and feelings with the help of contemporary equipment. Louis Darget and Hippolyte Baraduc created an entire compendium of recordings of the invisible [25]. Among the numerous images were those of thoughts or "psychicons", "luminous, living images of thoughts", as Baraduc put it.

The invention of the wireless telegraph gave a new impulse to attempts to capture thoughts on photographic plates and scientific interest in telepathy. The Russian physicist Nikolai Pavlov, who lectured on the theme "The radiant, wireless transfer of thoughts" in the $1910 \mathrm{~s}$, stated: "Humans are electromagnetic machines"; "our brain, like a telegraph station, can play the role of both dispatcher and receiver of electromagnetic waves"[26]. The concept of humans as permeable to radiation and existing in a permeable world refers to a widespread interpretation of the body of the medium as giving off and perceiving radiant matter. It is this phenomenon of mediums - in its scientificoccult interpretation - which became a new prototype for artists. The idea of the artist as a medium who can capture the ether's vibrations, register the invisible imprints of images within it and express them in paintings would be one

The fact that such ideas were current among the artists and poets of Larionov's circle is demonstrated by the expression "rays of thought" in Ilia Zdanevich's manifesto "Multi-Poetry": "Our poetry resembles the din of stations and markets, a multifaceted and many-faced murmur bursting with the rays of every thought". See Ilia Zdanevich, "Manifest vsechestva. Mnogovayapoeziya”, 1914. State Russian Museum Archive, f. 177 \# 22. 
of the most important concepts in the development of modernist art. Such ideas would be reflected in Larionov'srayonism, which represented "the radiant, wireless transfer of thoughts".

\section{CONCLUSION}

Larionov's rayonism did not, of course, exhaust the content or even the iconographic prototypes of radiation's mythologies. Rayonism was a synthetic concept, which allowed Larionov and his associates to place rayonism alongside everythingness, the final theory of the artist's Russian period. Larionov thought of rayonism as a concept which drew on various sources and referred to numerous contexts. I will briefly demonstrate one possible context, which is in contrast to the mythology of radiation. Icon painting, which Larionov studied seriously in the 1910s, may be yet another iconographic source for rayonist pictures. In a 1920 article, Larionov stressed the link between icons and abstract art: "Russian icon painters ... decisively moved towards abstraction. This abstraction was manifested in the use of schemes and canons related to a predefined manner, through which they are expressed the mystical and abstract meaning of life" [27].

One element of icons allowing for the expression of "the mystical and abstract meaning of life" was the strokes, lines or rays of gold leaf which covered clothing and objects and denoted matter transfigured by divine light. The structure and composition of these lines, which are reminiscent of the clusters of rays and linear flourishes that can be found in Larionov's pictures, may represent another pole in the painterly conception of rayonism, one that is counter to the positivistic-occult position.

In conclusion, I would like to note an important quality of Larionov's rayonism. His concept is devoid of gloomy seriousness and prophetic pathos. The early rayonist works Bull's Head and Rayonist Sausage and Mackerel are openly ironic and reference the primitive stage of the artist's work. Larionov's rayonism always retained a definite ambivalence: irony and contemplation, the scientific and the occult, play and daring immersion in the secrets of matter and spirit. The interweaving of such different (at first glance) vectors created the fantastic, radiant fabric of Larionov's rayonist works.
[5] Mikhail Larionov. "Rayonism" (1936) in N. Goncharova, M. Larionov. Research and Publications, Moscow, Nauka, 2003, p. 98.

[6] Gustave Le Bon. The Genesis and Disappearance of Substance, St Petersburg,Printing House "T-vaAndersona i Loitsyanskago", 1909, p 15 .

[7] M. Sedlov. Cesare Lombroso and Spiritualism, Moscow: Musaget, 1913 , p. 35.

[8] Naum Kotik. Emanation of Psychophysical Energy, Moscow,Izdanie V.M. Sablina, 1907, p. 72.

[9] Ibid, p. 61.

[10] Nikolai Pavlov. Rayonistic wireless transmitting of thought, Public lecture, Moscow, Printing House of K.L. Men'shov, 1910, p. 7.

[11] New Form of Rayonistic Energy, Compiled and published by the redaction "Derevenskayagazeta”,S. Petersburg, 1907, p. 12.

[12] Mikhail Larionov. Rayonism, Moscow, 1913, p. 19

[13] Mikhail Larionov. "Rayonism" (1936) in N. Goncharova, M. Larionov. Research and publications, Moscow, Nauka, 2003, p. 97 98.

[14] El'pe. Radii and Its Satellites (Rayonistic energy), St. Petersburg Publ. House of A.S. Suvorina, 1904, p. 317

[15] Clement Chéroux et al. The Perfect Medium: Photography and the Occult (New Haven, CT: Yale University Press, 2005).

[16] William Crooks. Rayonistic Substance or the Forth State of Bodies, Novgorod: Printing House of A.S. Fedorova, 1889, p. 25.

[17] Albert de Rochas. Light Radiation of a Man and the Movement of Sensitivity Outwards, Petrograd: Novyichelovek, 1915, p. 34.

[18] "Nardkevich-Iodko. Science News. IN the lab of Ya. O. Nardkevicha-Iodko" in V. Kiselev, Paradoxes of the "electric man", Minsk: Belorusskayanauka, 2007, p. 303

[19] MessiraPogorelsky. Electrophotosphenes and Energography as Proof of Physiological Polar Energy or So-called Animal Magnetism, St. Petersburg: Tipografiya V. Demakova, 1899.

[20] Mikhail Larionov. "Rayonism", (1936) in N. Goncharova, M. Larionov. Researh and publications, Moscow: Nauka, 2003, p. 102.

[21] Stewart Balfour and Peter Tait. The Unseen Universe or Physical Speculations on a Future State, New York: Macmillan, 1875, p. 156.

[22] Mikhail Larionov. "Rayonism", (1936) in N. Goncharova, M. Larionov. Researh and publications, Moscow: Nauka, 2003, p. 102.

[23] Ibid, p. 98.

[24] Ilia Zdanevich. "NataliyaGoncharova, MikhailLarionov" in Ilia Zdanevich, Futurism andvsechestvo 1912-1914, vol. 1 Moscow: Gileya, 2014, p. 115.

[25] HippolyteBaraduc. The Human Soul: Its Movements, its Lights and the Iconography of the Fluidic Invisible, Paris: Librairie international de la pensée nouvelle, 1913.

[26] Nikolai Pavlov. op. cit., p. 25

[27] Andrew Spira. The Avant-Garde Icon: Russian Avant-Garde Art and the Icon Painting Tradition, London, Lund Humphries, 2008, p. 59.

\section{REFERENCES}

[1] Mikhail Matiushin. "Opytkhudozhnikanovoimery", N. Khardzhiev, M. Matiushin, K. Malevich. To the History of Russian Avant-garde, Stockholm, Gileya, 1976, p. 160.

[2] Mikhail Larionov. "Mishen'. Predislovie k kataloguvystavki" in A. Kovalev, Mikhail Larionov v Rossii 1881-1915 gg., Moscow,Elizium, 2005, p. 357.

[3] Anthony Parton. "Russian 'Rayism', the Work and Theory of Mikhail Larionov and Natalya Goncharova 1912-1914: Ouspensky's Four-Dimensional Super Race?”, Leonardo, 16 (4), 1983, 298-305.

[4] Dmitri Sarabianov. "Mikhail Larionov i ob"edinenieMakovets" in Dmitri Sarabianov, Russian Painting'. The Awakening of Memory, Moscow, Iskusstvoznanie, 1998, p. 408. 